\title{
Science Mining and Clean Coal Technology in China
}

\author{
Wang Jiachen, Wang Lei, Yang Yang, and Yang Shengli
}

\begin{abstract}
Coal resource is the main energy resource in China. And from the structure of primary energy consumption, it can be seen that China is not rich in energy reserves, especially there is a shortage of oil gas resource. Fortunately, coal resource is rich relatively; therefore, coal is the most important energy in China, which takes a proportion about $70 \%$ in China energy consumption structure. This current situation cannot be changed in short term, however, reasonable exploitation and utilization of coal resource will play a vital role to energy strategy in the future. Thus, the concept of science mining arises under this background. Science mining was put forwarded by Chinese scholars based on the ideas of sustainable mining, circular economy, green mining and responsibility mining. The word is an accumulation of a large system: engineering, economic, management and social responsibility. How to develop scientific mining, which requires not only sophisticated theory as a guide, but also need to continued explore and summarize in practice, continue to improve science mining theory to guide the practical work. This paper describes the science mining connotation and clean coal technologies in science mining, it also raises some questions and suggestions of science mining.
\end{abstract}

Index Terms - Clean coal technologies, green mining, science mining, sustainable mining.

\section{INTRODUCTION}

Coal mining is an old industy. As early as 500 years BC, China has a large number of coal mine. Coal resources are fundation for human survival, but many people think that coal is unsafe and dirty in the process of mining, processing and utilizing due to inadequate understanding. As a country with huge coal production, China has already modern mining machinery equipments, such as fully mechanized tunelling, fully mechanized mining and transport equipment in open-pit mine, at the same time, mortality rate per million tons decreased year by year. Due to various restrictions, like geologic conditions, in China underground coal mining account for $90 \%$, mining conditions are big difference in different areas, coal production technologies and equipments present mutil-level structure, bigger mining intensity and safety pressure. In recent ten years, coal production greatly increased and its growth rate has gone far beyond safety production and scientific capacity, and social negative externality is aggravation. In addition, there are five restraining factors:

1) Complicated mining condition, harder mining, especially extremely-thick coal seam $\operatorname{mining}(\geqq 12 \mathrm{~m})$ is still challenging problem in the world, which restrict the development of science mining, green mining and science capacity;

Manuscript received July 11, 2014; revised November 14, 2014.

The authors are with China University of Mining and Technology, Beijing, 100083 Beijing, China (e-mail: 448422568@qq.com).
2) Lower recovery rate, serious resource waste;

3) Uncoordinated mining technology and equipment, increasing demand in resource utilization and evironmental protection, weak research in equipment reliability and material property;

4) Lack of talent, lower educated level, uncoordinated income and work;

5) Insufficient real cost [1].

For that reasons, it is very important to realize science mining and clean coal technology, and the key point is the development of technology.

At present, three aspects can be classified as science mining technologies, include: mining technology, equipment research and development, environmental protection and resource utilization technologies.

\section{Connotation And Development of SCience Mining}

Science mining is a new concept based on circular economy, green mining, clean technology and other theories. Qian Ming-gao who is an academician of the Chinese Academy of Engineering, has put forward the prototype of the green mining concept in 2003, and formally proposed theconcept of science mining in 2008. The concept of science mining is relatively abstract, but italso has a specific definition. In short, coal mining can be understood as "safe, efficient, highrecovery rate, mechanization or automation, green, environmental, full-cost", in other word, it can be also considered as the safe and efficient mining with the sustainable development in harmony with nature, environment and humanity. More specifically, the connotation of coal mining include [2]-[4]:

- Safety production. The primary safety production targets ought to reach or get close to the international advanced level of coal mining countries or the safety situation in coal mining is no worse than the security situation of other basic industries.

The mortality rate of miners per million tons in the world's other major mining countries in 2009 are as follows: Australia: 0.01, America: 0.018, South Africa: 0.07, Russia: 0.19, Poland: 0.266. In 2013, China is 3.08.

Most dangerous profession in the U.S., fishermen \& crabbers (111.8), loggers (86.4), pilots \& flight engineers (66.7), iron \& steel workers (45.5), oil \& gas production (43.9), farmers \& ranchers (38.4), coal miners (29.9), roofers (29.4), electrical power line installers/repairers (29.1), truck drivers (26.2), refuse \& recyclable material collectors (22.8), police \& patrol officers (21.4).

- Mining mechanization or automation. They are meant to increase productivity, to improve workers' safety and working conditions and to reduce personnel thus improve efficiency. The first line staff's work environment in coal mining should be not only safe, 
but also comfortable.

In recent years, the degree of mechanization of China's coal mine has been greatly improved, which accounts for $75 \%$. But it is less than mining advanced countries (95 to $100 \%)$. There is a basic consensus in the world - coal mine enterprise gets a balance point of revenue when fully staff efficiency achieve 10000t/person.year, however China is $700 t /$ person a year. If in U.S., coal production is 950 million ton/per year, its employees are about 100,000. But in China, coal mine employees are about 5.5million, coal production is about 3.8 billion ton per year.

- Improving the recovery rate of coal and associated resources, and saving or exploiting underground resources. Coal mining rate (also called recovery rate) is one of the core issues, which has plagued China's coal mining. Due to mining conditions, mining methods, resource exploration, reserve grade and other differences, the China's coal mining recovery rate is unstable. On a nationwide conservative estimates, the recovery rate is less than $50 \%$ of field reserves. Simultaneously, the recovery and utilization rate of gas resources, water resources and other associated resources are low as well. Fossil energy (resource) is a valuable resource formed by earth in thousands of years. Human need to face the issue that how to improve the exploitation rate, how to utilize and conserve the resources.

- Coal mining must operates within the capacity of the national or regional environment and water resource. It includes restoration or protection of the damaged ecology,air,water, rivers and other disturbances caused by the exploitation.

There is no doubt that mining has damage on the earth's original environment. The surface subsidence, vegetation destruction, underground and surface water drainage, river and air pollution and other damage caused by mining, which is one of the reasons that society has quite a lot of criticism to the mining industry, but the damage is inevitable. Simultaneously, ecology, environment, groundwater can achieve full or partial self-restore after a certain time. Mining should minimize the damage to the environment, and use the self-restore features and manual intervention to protect and restore the environment.

- Using the advanced science and technology to reduce the direct costs of coal mining.

Coal mining is a major source of national tax revenue. At the same time, due to the special nature of underground coal mining, which needs huge safety cost, land occupation and relocation of villages cost. It leads to higher costs of taxes, more safety inputs, land, labor and other costs, that is one of the main differences between mining and other industries. It makes China's coal mining costs higher than the surrounding or even other countries all over the world. The development of advanced mining technology and equipment aiming to reduce the direct costs of coal mining, improve labor efficiency and working conditions.

- In order to reflect the industry characteristics and the true value of coal, coal enterprise use the full cost method of coal mining and increasing wage costs method, which provides a solid foundation for determining the price of coal and maintainning a reasonable coal price.

Due to the particularity of coal mining, such as the destruction of the environment, security risk, the poor working conditions, some other mining cost need to be included (environmental remediation, worker safety risk and increasing wage).

- Realizing industrial circular economy and zero-discharge, and maximizing resource utilization.

The coal mining waster in the traditional sense, such as coal gangue, gas, mine water, wind and heat, is also a byproduct of mining and valuable resources. By extending industrial chain and fully utilizing the byproduct of coal mining, the large-scale systems can be achieved zero emissions.

The development process of science mining connotation and supporting technologies are shown in Fig. 1, four steps shown in Fig. 2:

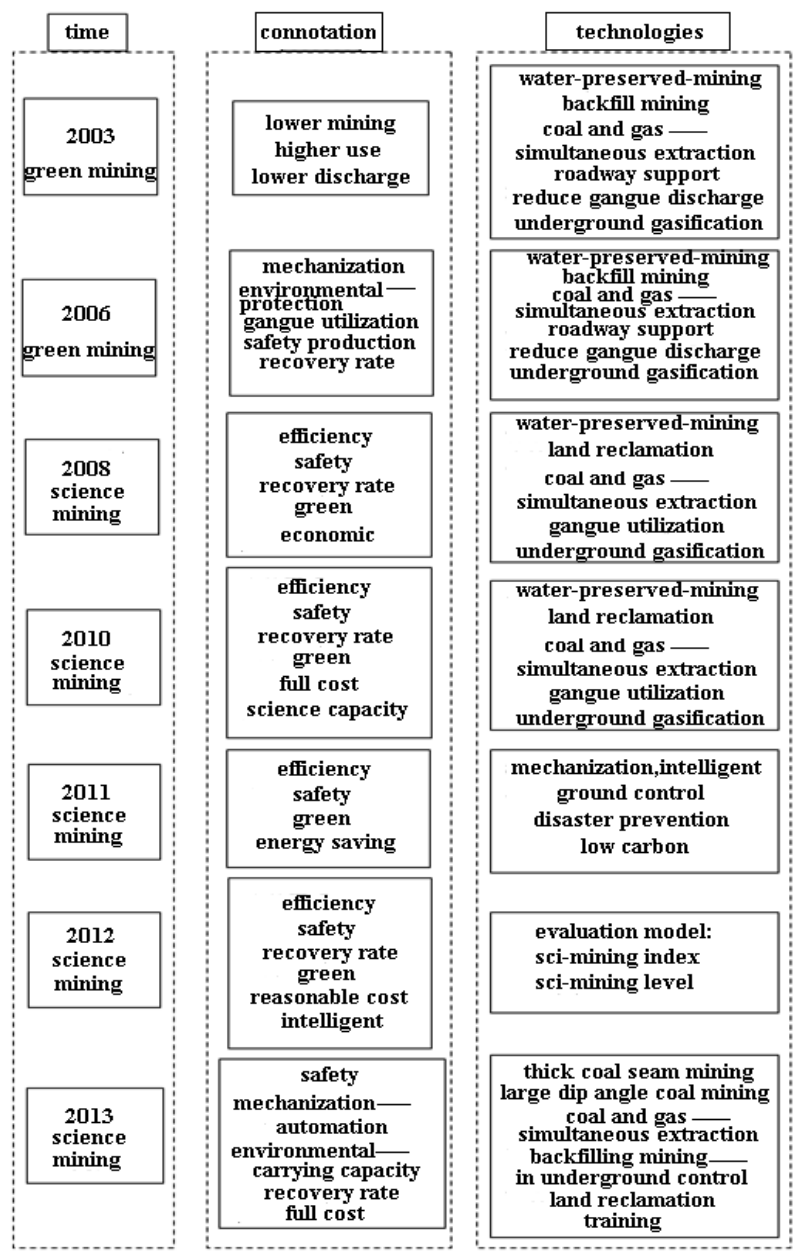

Fig. 1. The development process of science mining connotation and supporting technologies.

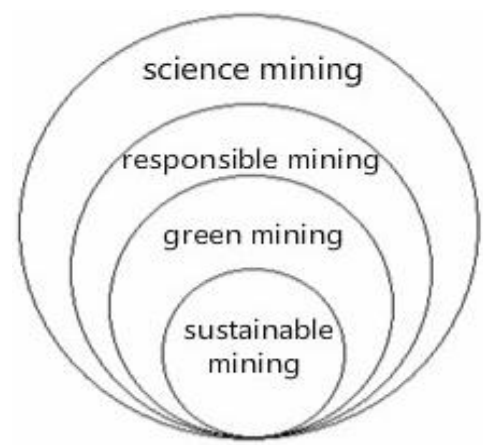

Fig. 2. Four steps of mining development. 


\section{The Key TeChNOlogIES OF SCIENCE MinING}

Coal is the main resource in coal-bearing strata, but some other resources are often associated, therefore, coal utilization should be considered in the process of mining design and planning. At the same time, the waste that produced by coal mining can also is used by processing. Coal enterprises should translate the traditional single linear model of economic development, which is "resources products - waste - renewable resources", into the feedback recycling economy development model, which is "resources - products - waste - renewable resources". That change is in order to extend the industrial chain and achieve low consumption, low emission, high efficiency, and obtain the greatest economic and social benefits when resource consumption is the minimum and environmental costs are the lowest (Fig. 3). In order to achieving the clean utilization and sustainable development in coal industry, the traditional model of economic growth that include higher consumption, higher waste and heavy pollution need to be changed.

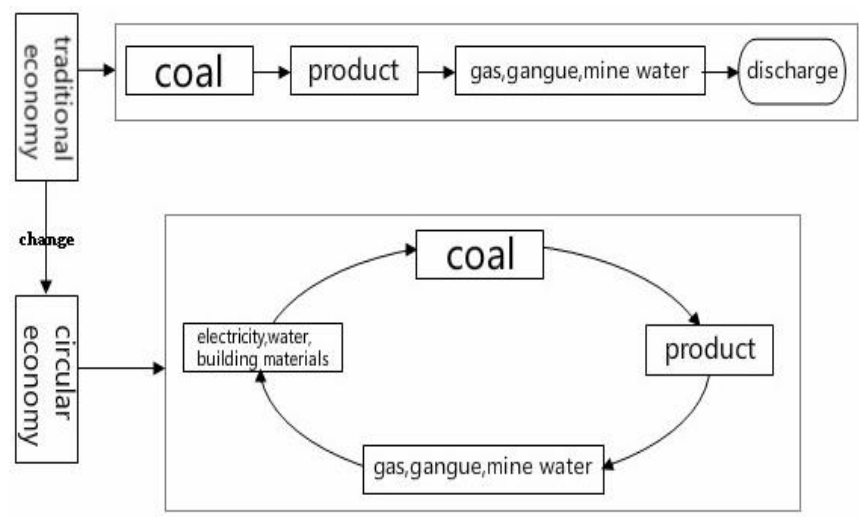

Fig. 3. Traditional economy and circular economy in coal industry.

Science mining and clean coal utilization depends on the development of technology. There are many technologies in science mining, including: mining technology (top coal caving in extremely-thick coal seam, top coal caving in thick coal seam, large dip angle coal mining, backfilling mining in ground control, coal and gas simultaneous extraction), equipment research and development (the main equipments in coal mining, automated mining and remote monitoring technology, information and communication technology), environmental protection and resource utilization technologies (the reclamation technology, the coal gangue utilization technology, underground gasification of coal technology). This paper only describes the technologies of clean coal.

\section{A. Land Reclamation Technology}

At present, there are two land reclamation technologies in subsidence areas caused by coal mining, which are filling reclamation and non-filling reclamation. The filling reclamation technology often use mining solid wastes (such as gangue and fly-ash) to filling into goaf, it aims to restore original surface height in order to achieve land reclamation. The technology has the dual effects what bury solid waste and reclaim land. Filling reclamation techonolgy solves problem of subsidence land reclamation and improves the economic environment efficiency significantly. But the possibility of secondary pollution and the reclaimed soil productivity is not enough. Therefore, non-filling reclamation technology is widely application. According to the different types and the extent of damage, the non-filling reclamation technology are mainly divided into the direct use method, the trimming method, dredging and draining method and deepening shallow pad method. Recently, the research on mine land reclamation and ecological reconstruction is very active at home and abroad. Land reclamation conclude engineering reclamation and biological reclamation, many researchers and practice has been done on those two aspects, a lot of progress has been made ,such as the influence on land, integrated ecological and environmental improvement on wasteland, suitable excellent pioneer plant species selection and cultivation, soil improvement and fertilization, abandoned soil characteristics and improvement, abandoned land reclamation and microbial reclamation technology. But, the artificial vegetation coverage is still very low in the mine area, ecological effects of revegetation is still not clear, biological species are very single, the stress resistance is poor, some short-term ecological managements occurred mainly due to less real consideration about the soil ecosystem stability and sustainability, so it should start from building a long-term stable ecosystem factors for land restoration to ensure the continuity and stability of land reclamation.

\section{B. The Coal Gngue Utilization Technology}

Another coal waste (gangue's production) is growing, which is more than 100 million tons per year of coal gangue, and accumulated gangue over the years has exceeded 30 million tons, covering 20,000 hectares, there are more than 1,500 large-scale waste dump. Except for backfilling mining, the large number of coal gangue is still stacked in air.It takes up a lot of land, and produces large amounts of acidic water or carries heavy metal ions in water, soil and the groundwater is polluted by inslolation, raining, weathering, decomposition. Nearly $1 / 3$ of waste dump spontaneous combustion due to the existent pyrite and carbonaceous material, therefore toxic gases will be produced. After the sedimentation of these toxic gases, the soluble sulfate makes soil acidification and increases the bioavailability, so removing the sulfur is the key problem. A basic condition that is suitable for plant growth should be constructed to achieve ecological reconstruction of gangue hill and ecological environment of inprovement.

\section{1) Gangue sintered brick techonolgy}

Gangue sintered brick technology mainly uses coal gangue as raw material, coal gangue sintered brick technology mainly using coal gangue as raw material, using the calorific value in gangue at calcining kiln to achieve a fixed temperature combustion, sintered brick is energy-saving environmental protection and durable. The application of this technology not only replaces the clay blank, but also reduce the traditional reliance on coal resource, and achieving a "blocking without soil, brick without coal", reducing damage to the environment, increasing resource utilization, saving coal resource. Meanwhile, through the use of advanced processing method of ash, the environment pollution caused by burning dust and harmful associated gases will be reduced. 


\section{2) Gangue power generation technology}

The coal gangue power generation is using coal gangue in the combustion furnace to heat water into steam, then steam drives turbine, turbine turns a generator to complete power, in this process, three times energy conversion happened:the chemical energy of the coal gangue---steam heat---steam turbine rotating mechanical energy - electric energy by generators. The use of coal gangue to generate electricity improving the comprehensive utilization of energy, saving the energy, reducing the pollution to the environment, reducing the emissions of harmful gases [5]. The power generation of gangue shown in Fig. 4.

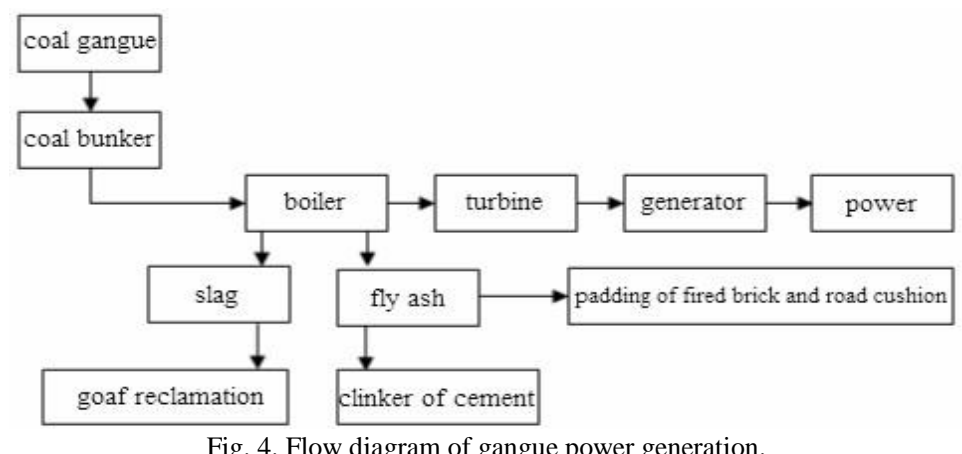

\section{Underground Coal Gasification Technology}

Underground coal gasification technology is to burn the buried underground coal, the produced combustible gas will be put out through chemical reaction and thermal effect of coal. Underground coal gasification technology can recycle abandoned coal mine resources. The utilization of under -ground coal gasification technology can use about $50 \%$ of abandoned coal resources [6]. It also can be used for difficult and unsafe thin seam, deep coal seams and 'under building, railway and water' mining, and coal seam with high sulfur, high-ash, high gas. Underground gasification gas can not only be used as direct civil gas and power generation, but also be used to extract pure hydrogen or as raw material gas of synthetic oil of ammonia, methanol, dimethyl ether. Therefore, underground coal gasification technology has satisfying economic and environmental benefit, and greatly improving the utilization of coal resources, it is an important direction of research and development of clean coal technology in China.

\section{CONCLUSION}

The development of coal industry in China need to do further study and research in theory and practice, therefore, the development issues of China's coal industry discussed from the theory and practice of science mining, which not only has significance for the theory of science mining, but also has a high practical value for the entire coal industry. For the moment, science mining still faces the problems: 1 ) low level on technical achievements transformation and application, 2) insufficient technology innovation capability, 3) unbalanced development of information system, 4) imperfect market and competitive mechanisms, 5) incomplete management innovation system.

In conclusion, innovation and development of technologies and equipments are essential questions to realize science mining. In the process of development and utilization of coal resources, the supportive technical system should be applied in order to enhance recovery rate, reduce negative external effects, and realize clean utilization.

\section{ACKNOWLEDGMENT}

Project (U1361209) was supported by the National Natural Science Foundation of China - Coal Joint Foundation.

\section{REFERENCES}

[1] J. C. Wang, "The connotation and technical progress of scientific coal mining," Coal and Chemical Industry, vol. 37, pp. 5-9, Jan. 2014.

[2] M. G. Qian, J. L. Xu, and X. X. Liao, "Green mining technology in coal mine," International Journal of Mining Science and Technology, vol. 32, pp. 343-347, July 2003.

[3] M. G. Qian, J. L. Xu, and X. X. Liao, "On scientized mining," Journal of Mining and Safety Engineering, vol. 25. pp. 1-10, March 2008.

[4] J. C. Wang and M. G. Qian, "Strategic thinking on cultivating excellent engineer-talent cultivation of science mining," Coal Higher Education, vol. 29. pp. 1-4, Sep. 2011.

[5] D. G. Cao, The Development Model and Technology System of Circular Economy in Coal Industry, Beijing: Geological Publishing Press, 2007, ch. 3 .

[6] J. C. Wang, L. Wang, and Y. Li, "The coal and gas co-extraction technology in China," in Proc. 46th US Rock Mechanics/Geomechanics Symposium, Chicago, USA, June 2012.

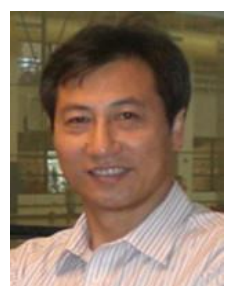

Wang Jiachen was born in China, on March 25 , 1963. He received his B.E. degree in mining engineering from Anshan Iron and Steel Institute, in 1982. He received his M.E. degree in mining engineering from University of Science and Technology Beijing, in 1987. Then he received his $\mathrm{Ph} . \mathrm{D}$. degree in mining engineering from China University of Mining and Technology, Beijing, in 1993. He was a post doctor in mining engineering at University of Science and Technology Beijing, in 1995.

$\mathrm{He}$ is the dean of Faculty of Resources and Safety Engineering, he had published 3 academic works including Random analysis principle of slope engineering (Beijing, Coal Industry Press, 1996), Thick coal seam mining theory and technology (Beijing, metallurgical industry Press, 2009), Introduction to energy engineering (Beijing, China University of Mining and Technology Press, 2014). He also had published about 90 papers, 40 papers indexed by SCI or EI. His research interests include science coal mining, thick coal seam mining, top coal caving, ground control, mining engineering and system reliability.

Prof. Wang is one of the chief academic leaders of Mining Engineering National Key Disciplines, enjoying special government allowances of the state council, the national outstanding teacher. He awarded 2 awards on National Award for Science and Technology Progress, 18 awards on Province Award for Science and Technology Progress, 4 National invention patents. 